\title{
Didática da Gestão do Conhecimento em Cursos de Graduação em Administração
}

\author{
Adelcio Machado dos Santos ${ }^{1}$ \\ Fernando José Spanhol ${ }^{2}$ \\ Francisco Antônio Pereira Fialho ${ }^{3}$ \\ Rudimar Antunes da Rocha
}

\section{Resumo}

Na sociedade da informação, o conhecimento se transforma no fator-chave da economia pós-industrial e no principal determinante da mudança ocupacional. Por isso, a Gestão do Conhecimento se configura como uma importante metodologia à disposição das organizações e contribui para criar, compartilhar e disseminar o conhecimento no intento de auxiliá-la a enfrentar da melhor forma possível as forças que o ambiente exerce. A Gestão do Conhecimento está inserida na educação superior, de modo que a didática voltada para a Gestão do Conhecimento deve focar o ensino multidisciplinar e reflexivo. No ensino da Gestão do Conhecimento a relação pedagógica não deve se configurar de forma unidirecional, mas sim permitir a participação do aluno, constituindo-se o professor como um facilitador do processo de aprendizado. Este artigo, pautado pelo método dedutivo, tem por objetivo analisar o papel da didática da Gestão do Conhecimento no âmbito dos Cursos de Graduação em Administração, colhendo a conclusão de sua relevância para o desenvolvimento das competências normatizadas para o profissional egresso do aludido curso.

Palavras-chave: Gestão do Conhecimento. Educação. Sociedade da informação.

\footnotetext{
${ }^{1}$ Pós-Doutorando em Engenharia e Gestão do Conhecimento pela Universidade Federal de Santa Catarina. Docente e pesquisador da Universidade do Oeste de Santa Catarina (UNOESC). Presidente do Conselho Estadual de Educação de Santa Catarina. Endereço: Av. Osmar Cunha, n 183, Bloco "B", Sala 303 -88015-100, Florianópolis-SC-Brasil. E-mail: adelcio@redel.com.br.

${ }^{2}$ Docente e Pesquisador do Programa Pós-Graduação em Engenharia e Gestão do Conhecimento (UFSC); Doutor em Engenharia de Produção (UFSC). Gerente Geral do Laboratório de Educação a Distância da UFSC. Endereço: Centro Universitário João Davi Ferreira Lima, Bairro Trindade -88040-970, Florianópolis-SC-Brasil.

${ }^{3}$ Docente e Pesquisador do Programa de Pós-Graduação de Engenharia e Gestão do Conhecimento (UFSC); Doutor em Engenharia de Produção (UFSC). Endereço: EGC Campus Centro Universitário João Davi Ferreira Lima, Bairro Trindade -88040-970, Florianópolis - SC - Brasil.

${ }^{4}$ Doutorado em Engenharia de Produção pela Universidade Federal de Santa Catarina. Professor Associado I do Departamento de Ciências da Administração da Universidade Federal de Santa Catarina. Endereço: Universidade Federal de Santa Catarina, Centro Sócio-Econômico, Departamento de Ciências da Administração. Campus Universitário Prof. João David Ferreira Limaus - Trindade-UFSC, CEP $88040-900$ Florianópolis-SC-Brasil. E-mail: rrudimar@hotmail.com. Artigo recebido em: 05/03/2009. Aceito em: 15/10/2009. Membro do Corpo Editorial Científico responsável pelo processo editorial: João Nilo Linhares.
} 


\section{Introdução}

A formação do conhecimento se constitui como um investimento fundamental nos países desenvolvidos e tem recebido cada vez mais destaque nas organizações. O retorno que um país ou uma organização obtém sobre o conhecimento, na atualidade, representa um fator determinante de sua competitividade. Destarte, verifica-se que, em um grau cada vez maior, o conhecimento se torna decisivo para o sucesso econômico e social de uma organização $e$ a principal diferença entre países e organizações diz respeito à capacidade de produzir conhecimento. Isso significa que o conhecimento se transformou em um elemento fundamental da dinâmica da nova ordem mundial: conhecimento e informação são, hodiernamente, recursos estratégicos $e$ os agentes transformadores da sociedade.

Kumar (1997) acrescenta que na estrutura da sociedade da informação, o conhecimento não apenas determina, em um grau sem precedentes, a inovação tecnológica e o crescimento econômico, mas se torna a atividade-chave da economia e a principal determinante da mudança ocupacional. Associada a essa nova realidade produtiva tem-se o desenvolvimento das Tecnologias de Informação e Comunicação (TICs), as quais facilitam a transmissão da informação para gerar conhecimentos novos a todo instante. Com isso, tem-se o advento da era da comunicação, da sociedade pós-industrial ou sociedade do conhecimento.

A sociedade pós-industrial, consoante o magistério dado a lume por Kumar (1997), emana de um processo de transformação social, em que a informação e o conhecimento adquirem relevância central. O axioma central da sociedade pós-industrial jaz na evolução de uma sociedade de serviços e o crescimento célere de oportunidades de emprego para profissionais liberais e de nível técnico. Fleury e Fleury (2004) pontuam que na economia pautada em conhecimento, o que mais adiciona valor são as atividades inteligentes, enquanto as atividades rotineiras, manuais, passam a ser cada vez menos importantes. O trabalho intelectual interessa sempre mais, demo que demanda incentivo. Conseguintemente, as organizações que operam com base no novo paradigma do conhecimento focam as atividades realmente agregadoras de valor, ou, em outros termos, mais intensivas em inteligência.

Em meio a essa realidade, percebe-se um aumento constante do conhecimento, o qual não é somente quantitativo, mas também qualitativo. Enquanto que os meios de comunicação antigos transmitiam a mensagem 
de forma padronizada a espectadores de massa uniformes, por meio das novas tecnologias de comunicação viabilizou-se a concentração, a segmentação $e$ a divisão de transmissores e receptores em unidades separadas $e$ descontínuas. Destarte, é possível processar uma informação, recuperá-la ou selecioná-la com o fim de satisfazer as necessidades mais especializadas e individualizadas. Essa importância do conhecimento também tem incentivado uma mudança ocupacional dos trabalhadores. A quantidade de trabalhadores empregados no setor de produção da informação tem aumentado consideravelmente, sendo que a informação é produzida em massa, do mesmo modo que é produzido um objeto físico de consumo. Isso resulta na modificação dos mecanismos estruturais da produção.

Isso pode ser observado na Resolução n ${ }^{\circ}$ 4, de 13 de julho de 2005 do Conselho Nacional de Educação da câmara de Educação Superior que institui que:

Artigo $1^{\circ}$ : A presente Resolução institui as Diretrizes Curriculares Nacionais do Curso de Graduação em Administração, bacharelado, a serem observadas pelas Instituições de Ensino Superior em sua organização curricular (BRASIL, 2005).

Entrementes em que a Gestão do Conhecimento configura-se instrumento indispensável dentro das organizações, para que coordene adequadamente o conhecimento, ela também adquire espaço em meio ao ensino universitário. Diante disso, para que possa ser implementada em uma organização, a mesma deve dispor de pessoas dotadas de conhecimento acerca das atividades relacionadas à Gestão do Conhecimento, ou seja, pessoas que tenham estudado essa disciplina. Dessarte, baseado na Gestão do Conhecimento, matéria integrante de diversos cursos de educação superior, faz-se mister discutir a questão didática inerente a essa disciplina. Em outros termos, configurou-se didática específica aplicada à Gestão do Conhecimento e seu ensino na educação superior? 


\section{Dado, Informação e Conhecimento}

Antes de adentrar diretamente os pressupostos e atividades relacionadas à Gestão do Conhecimento, torna-se relevante abordar a disparidade existente entre dado, informação e conhecimento, procurando conceituar cada um desses elementos e compreender a interrelação. Essa interação que ocorre entre os dados e as informações constitui o fundamento da Gestão do Conhecimento. O termo dado, que com frequência pode ser encontrado na literatura ligada à área de ciência da informação e informática, é conceituado por Lapa (2004, p. 24) como "um conjunto de registro qualitativo ou quantitativo conhecido" que, ao ser agrupado, organizado, categorizado e padronizado de modo adequado se transforma em informação. Para Silva Filho e Silva (2005, p. 27), dados

[...] são anotações objetivas relativas à vida da organização, descrevem uma realidade. São o registro estruturado do que aconteceu na organização, não envolvem juízos de valor ou interpretações para a tomada de decisões.

Em termos de características físicas, o dado pode ser entendido como um elemento da informação, um conjunto de letras, números ou dígitos, que, ao ser tomado de modo isolado, não transmite qualquer conhecimento, isto é, não contém um significado claro (LAPA, 2004). A palavra informação, no juízo de Lapa (2004), pode ser interpretada como um dado trabalhado, útil, tratado, o qual possui um valor significativo atribuído ou agregado a ele e com um sentido natural e lógico para quem usa a informação. No entanto, num segundo momento, cuja informação é trabalhada por pessoas ou por recursos computacionais permitindo a geração de cenários, simulações e oportunidades, já se torna possível questionar se não se tornou um conhecimento.

No que concerne ao conhecimento, este é concebido por Lapa (2004, p. 26) como sendo "um conjunto de argumentos e explicações que interpretam um conjunto de informações". Trata-se de conceitos e argumentos lógicos, fundamentais e abstratos que interligam e dão significado a fatos concretos, envolvendo, portanto, hipóteses, teorias, modelos e leis. Em outra perspectiva de conceituação, o conhecimento pode também ser visto como uma combinação de instintos, ideias, informações, regras e procedimentos que são responsáveis por guiar ações e decisões. Nesse sentido, o conheci- 
mento abrange experiências vivenciadas, valores, informação contextual, entre outros fatores que proporcionam uma estrutura para a avaliação e incorporação de novas experiências e informações. Nas empresas, esse conhecimento costuma estar embutido não apenas em documentos ou repositórios, mas também em rotinas, processos, práticas e normas organizacionais (LAPA, 2004).

\section{Gestão do Conhecimento}

A construção e a utilização do conhecimento compreendem um desafio para as empresas atuais. Tanto o conhecimento quanto as experiências se encontram dispersos em meio à organização e se concentram, comumente, em determinados indivíduos ou unidades de trabalho. Para que uma empresa obtenha sucesso, ela necessita saber localizar esse conhecimento especializado para transformá-lo em ação (CHOO, 2003). Em consonância com o magistério de Drucker (2001), o que hodiernamente significa conhecimento é a informação que se efetiva em ação, a informação focalizada nos resultados. Dessa forma, cabe às empresas localizar e transformar o conhecimento em ação e, por conseguinte, em resultados.

Com base nessa necessidade das organizações, tem-se o desenvolvimento da Gestão do Conhecimento que, segundo Silva Filho e Silva (2005), objetiva, fundamentalmente, criar, compartilhar e disseminar o conhecimento para que a organização possa enfrentar melhor as forças que o ambiente exerce sobre a organização. A Gestão do Conhecimento pode ser conceituada como "uma metodologia empresarial que engloba todo o processo organizacional para atingir a combinação sinérgica do processamento de dados e informações, da tecnologia da informática e a da criatividade do ser humano" com o fim de maximizar o uso de seu acervo tecnológico (CALDAS; AMARAL, 2001).

Essa metodologia deve proporcionar à empresa sua constante adaptação a um meio ambiente em evolução permanente, com a finalidade de formatar esse acervo, disponibilizar as informações ou as experiências acumuladas e estar permeável a adicionar novos patamares do saber para aprimorar o seu processo decisório. Destarte, a Gestão do Conhecimento pressupõe a identificação, análise, interpretação e avaliação dos conhecimentos específicos para empregá-los na otimização dos recursos da empresa, no atendimento às necessidades do seu mercado e com um direcionamento que 
vise uma adequação às atuais circunstâncias e às futuras mudanças do seu meio ambiente (CALDAS; AMARAL, 2001).

A Gestão do Conhecimento envolve, num primeiro momento, o gerenciamento do processo de criação de conhecimento dentro de uma organização. A criação do conhecimento é conceituada por Zabot e Silva (2002, p. 71), como "a capacidade que uma empresa possui de criar conhecimento, disseminá-lo na organização e incorporá-lo a produtos, serviços e sistemas".

A criação ou o desenvolvimento do conhecimento, consoante expõem Nonaka e Tackeuchi (1997 apud LARA, 2004), deve ser entendido como um processo que amplia o conhecimento desenvolvido por pessoas no contexto organizacional. A interação existente entre o conhecimento tácito e o explícito implica em quatro modos de conversão do conhecimento: a) do tácito para o tácito: nesse caso se dá o compartilhamento de experiências e, com base nisso, a criação do conhecimento tácito, como modelos mentais ou habilidades técnicas compartilhadas. A experiência é o principal fator para a aquisição do conhecimento tácito; b) do tácito para o explícito: nesse processo de conversão ocorre a articulação do conhecimento tácito em conceitos explícitos, isto é, desenvolve-se um processo de criação do conhecimento perfeito, pelo fato de se tornar conhecimento explícito, expresso na forma de metáforas, analogias, conceitos, hipóteses ou modelos. A externalização desse conhecimento ocorre por meio de diálogo ou pela reflexão coletiva; c) do explícito para o explícito: essa forma de conversão se dá por intermédio da sistematização de conceitos em um sistema de conhecimento, incluindo a combinação de diferentes conjuntos de conhecimento explícito. A combinação se desenvolve através de documentos, reuniões, conversas ao telefone ou redes de comunicação informatizadas. Novos conhecimentos podem advir da reconfiguração das informações por meio da classificação, do acréscimo, da combinação e da categorização do conhecimento explícito; d) do explícito para o tácito: nesse caso recorre-se ao procedimento da dedução. Esse processo está relacionado com a aprendizagem por meio da prática. O modo mais comum para esse processo consiste na verbalização e a diagramação do conhecimento sob a forma de documentos, manuais ou histórias orais.

Choo (2003) afirma que as organizações criam e exploram conhecimento no intento de desenvolver novas capacidades e inovações por meio de três atividades desenvolvidas conjuntamente: 1) gerar e compartilhar conhecimento tácito; 2) testar e criar protótipos de conhecimento explícito; e 3) extrair e aproveitar conhecimento externo. O conhecimento tácito, embora pessoal e difícil de ser codificado em termos formais, pode, no entanto, ser 
compartilhado e transmitido de maneira informal, através de recursos de comunicação como as metáforas, analogias, modelos e histórias. Com base em um processo de combinação, teste e refinamento, o conhecimento tácito é progressivamente transformado em formas mais explícitas e tangíveis, como inovações, produtos ou serviços aprimorados ou novas capacidades.

A Gestão do Conhecimento também se encontra diretamente vinculada à Gestão do Capital Intelectual da organização, focando, por conseguinte, o desenvolvimento do capital humano e a aprendizagem organizacional. Todos esses procedimentos são indispensáveis para que uma organização possa se transformar em uma organização do conhecimento, criando, armazenando e distribuindo conhecimento no intento de otimizar os resultados econômicos da mesma. O capital intelectual, no entender de Brooking (1996 apud ANTUNES, 2000, p. 78), é

[...] uma combinação de ativos intangíveis, frutos das mudanças nas áreas da tecnologia da informação, mídia $e$ comunicação, que trazem benefícios intangíveis para as empresas e que capacitam seu funcionamento.

De acordo com Antunes (2000), o capital intelectual pode ser dividido em quatro categorias, a saber: a) ativos de mercado: é o potencial que a empresa possui em virtude dos intangíveis, que estão relacionados ao mercado, como marca, clientes, lealdade dos clientes, negócios recorrentes, negócios em andamento, canais de distribuição, franquias, entre outros; b) ativos humanos: diz respeito aos benefícios que os indivíduos podem proporcionar às organizações através de sua expertise, criatividade, conhecimento, habilidade para resolver problemas, tudo abordado de modo coletivo e dinâmico; c) ativos de propriedade intelectual: são aqueles ativos que exigem a proteção legal para proporcionarem às organizações benefícios, como o know-how, segredos industriais, copyright, patentes, designs, entre outros; d) ativos de infraestrutura: compreende as tecnologias, as metodologias e os processos empregados como cultura, sistema de informação, métodos gerenciais, aceitação de risco e banco de dados de clientes.

O capital humano ou ativo humano, segundo Zabot e Silva (2002), diz respeito àquelas pessoas estudadas e especializadas, que são importantes recursos para a empresa, uma vez que coordenam todo o processo de geração e compartilhamento do conhecimento. Os autores acrescentam que visto como a característica mais marcante da era do conhecimento, o surgimento 
do capital humano aparece como a força dominante da economia. Embora na sociedade industrial o capital físico e o financeiro se constituíam em fatores críticos para o sucesso, na economia do conhecimento a importância relativa do capital físico diminui à medida que a tecnologia se torna mais barata e a qualificação, o conhecimento e as habilidades das pessoas crescem em importância. Ademais disso, enquanto na sociedade industrial a educação era direcionada de forma exclusiva para a alfabetização e o provimento de treinamento técnico, na era do conhecimento e da informação a exigência da educação torna-se universal e seus níveis crescem para as novas áreas de conhecimentos que requerem mais treinamento e educação atualizada para sua aplicação (ZABOT; SILVA, 2002).

O capital humano, outrossim, constitui-se fonte dos ativos intangíveis em uma organização. De acordo com Zabot e Silva (2002), o fato de as pessoas serem os únicos verdadeiros agentes na empresa, fonte dos ativos intangíveis, e de essas pessoas estarem constantemente direcionando seus esforços em dois sentidos, para fora da empresa no relacionamento com os clientes, e para dentro, mantendo e construindo a organização, permite que tais ativos sejam classificados como um grupo de três elementos: a) competência das pessoas: é considerada como ativo intangível, pois, mesmo que não possa ser propriedade de ninguém, exceto da própria pessoa, é inviável conceber uma organização sem pessoas. Em certas organizações do conhecimento existem poucos equipamentos e, como apenas as pessoas podem agir, elas tornam-se tanto os mentores do equipamento quanto os próprios equipamentos; b) estrutura interna: engloba conceitos, patentes, modelos e sistemas, bem como a cultura organizacional. Uma organização e sua estrutura é resultado da criação das pessoas, por meio da interação mútua, desenvolvendo, desse modo, o ambiente; c) estrutura externa: está relacionada não apenas às relações com clientes e fornecedores, mas também a marcas e à própria imagem da empresa e sua reputação. O valor desses ativos é determinado pelo grau de satisfação com que a empresa soluciona os problemas de seus clientes, algo também difícil de quantificar em termos monetários e que torna-se mutável com o passar do tempo.

O desenvolvimento do capital humano está centrado, sobretudo, no desenvolvimento das competências. Em uma sociedade na qual a competitividade cresce sempre mais, a competência torna-se um diferencial e um requisito para um desempenho satisfatório das pessoas e das organizações. Uma competência é uma combinação de conhecimentos e comportamentos, conhecimentos estes que reúnem características, tais como, forma- 
ção, treinamento, experiência, autodesenvolvimento, habilidades, interesses e vontade (RESENDE, 2003). Nas organizações do conhecimento, algumas competências são indispensáveis: aprender a aprender; comunicação e colaboração (espírito de equipe); raciocínio criativo e resolução de problemas, esperando-se que os colaboradores descubram por si próprios como aprimorar seu trabalho; conhecimento tecnológico, conhecimentos e habilidades globais; desenvolvimento de liderança e autogerenciamento de carreira.

Nesse sentido, Silva Filho e Silva (2005) também sustentam que para criar, compartilhar e disseminar o conhecimento no intento de transformá-lo em novas tecnologias e novos produtos, as organizações precisam aprender. Em relação à aprendizagem, torna-se relevante distinguir entre os conceitos de "aprendizagem organizacional" e "organização de aprendizagem". De acordo com Ruas, Antonello e Boff (2005), a aprendizagem organizacional tem sido vista como a busca para manter e desenvolver competitividade, produtividade e inovação em condições tecnológicas e de mercado incertas. $\mathrm{Na}$ literatura, comumente, é delineada como um grupo de percursos pelos quais as empresas concebem e organizam conhecimento e rotinas em suas atividades e em sua cultura, pois adaptam e desenvolvem eficácia organizacional através do desenvolvimento e aproveitamento das diversas competências de seu capital humano.

Importa observar que o conceito de aprendizagem organizacional evoluiu rapidamente para cobrir vários aspectos do gerenciamento organizacional. Os pesquisadores e profissionais tentam prover uma descrição holística dessa área e terminam criando uma diversidade de definições, as quais podem ser agrupadas em seis áreas de enfoques diversos: socialização da aprendizagem individual, processo-sistema, cultura, gestão do conhecimento e melhoria contínua e inovação (RUAS; ANTONELLO; BOFF, 2005). Nos estudos acerca da aprendizagem organizacional, os estudiosos se concentram na descrição e análise distanciada dos processos envolvidos na aprendizagem individual e coletiva, tanto dentro como entre as organizações. Por sua vez, nos trabalhos sobre a organização de aprendizagem, os estudiosos estão preocupados em estabelecer instrumentos metodológicos de diagnóstico e avaliação dos processos de aprendizagem.

Por conseguinte, as organizações de aprendizagem se caracterizam por criar, compartilhar e disseminar o conhecimento. Já as organizações que aprendem, no intento de enfrentar os desafios do ambiente interno e externo, procuram transformar o conhecimento em novas tecnologias e em novos 
produtos (SILVA FILHO; SILVA, 2005). Ressalta-se, ainda, que a tendência consiste em imaginar que a aprendizagem na organização se proceda de uma maneira planejada, como resposta a uma decisão deliberada da gerência. Mas, conforme destaca Silva Filho e Silva (2005), acontecimentos inesperados, tanto internos quanto externos à organização, limitam as possibilidades da aprendizagem planejada. Portanto, embora a organização possa aprender de forma planejada, é nas atividades diárias e rotineiras que a aprendizagem se processa.

De acordo com a Resolução n 4/2005, do CNE/CES (BRASIL, 2005), é imperativo que os cursos de graduação em administração ensejem como perfil desejado de seus formandos a

[...] capacitação e aptidão para compreender as questões científicas, técnicas, sociais e econômicas da produção $e$ de seu gerenciamento, observados níveis graduais do processo de tomada de decisão, bem como para desenvolver gerenciamento qualitativo e adequado, revelando a assimilação de novas informações e apresentando flexibilidade intelectual e adaptabilidade contextualizada no trato de situações diversas, presentes ou emergentes, nos vários segmentos do campo de atuação do administrador.

Destarte, em decorrência de suas demandas, é natural que a noção de Administração enquanto curso de graduação ofereça desafios imediatos e, consequentemente, diversos dilemas pedagógicos de difícil solução.

Presentemente, os cursos de graduação em administração têm seus currículos básicos compostos de acordo com as diretrizes do Ministério da Educação e são complementados com disciplinas que distinguem as formações características de suas habilidades, suas peculiaridades regionais e até mesmo da sua formação geral de cidadania.

A Resolução nº 4/2005 do CNE/CES (BRASIL, 2005) enfatiza que:

Art. $4^{\circ} \mathrm{O}$ Curso de Graduação em Administração deve possibilitar a formação profissional que revele, pelo menos, as seguintes competências e habilidades:

I - reconhecer e definir problemas, equacionar soluções, pensar estrategicamente, introduzir modificações no processo produtivo, atuar preventivamente, transferir e gene- 
ralizar conhecimentos e exercer, em diferentes graus de complexidade, o processo da tomada de decisão;

II - desenvolver expressão e comunicação compatíveis com o exercício profissional, inclusive nos processos de negociação e nas comunicações interpessoais ou intergrupais; III - refletir e atuar criticamente sobre a esfera da produção, compreendendo sua posição e função na estrutura produtiva sob seu controle e gerenciamento;

IV - desenvolver raciocínio lógico, crítico e analítico para operar com valores e formulações matemáticas presentes nas relações formais e causais entre fenômenos produtivos, administrativos e de controle, bem assim expressando-se de modo crítico e criativo diante dos diferentes contextos organizacionais e sociais;

$\mathrm{V}$ - ter iniciativa, criatividade, determinação, vontade política e administrativa, vontade de aprender, abertura às mudanças e consciência da qualidade e das implicações éticas do seu exercício profissional;

VI - desenvolver capacidade de transferir conhecimentos da vida e da experiência cotidianas para o ambiente de trabalho e do seu campo de atuação profissional, em diferentes modelos organizacionais, revelando-se profissional adaptável;

VII - desenvolver capacidade para elaborar, implementar e consolidar projetos em organizações; $e$

VIII - desenvolver capacidade para realizar consultoria em gestão e administração, pareceres e perícias administrativas, gerenciais, organizacionais, estratégicos e operacionais.

Drucker (1997, p. 198) afirma que a Administração seria agora

[...] o que a tradição chamava de arte liberal: [liberal] por lidar com aspectos fundamentais do conhecimento, do autoconhecimento, da sabedoria e da liderança; [arte] por ser uma prática e uma aplicação.

Em suma, colima-se que a Gestão do Conhecimento diz respeito a uma diversidade de atividades que focam o capital intelectual e os ativos intangíveis da empresa, com a finalidade de trabalhar e organizar dados e informa- 
ções, transformando-os em conhecimento para que a empresa alcance os objetivos traçados. Esse conhecimento que é criado necessita ser compartilhado e multiplicado dentro da organização, o que só é possível por meio de seu uso.

\section{A Importância da Didática}

A didática se configura disciplina cujo objeto específico concerne à técnica de ensino. Portanto, estuda a técnica de ensino em todos os seus aspectos práticos e operacionais, podendo ser conceituada como, segundo Piletti (1990, p. 43), "a técnica de estimular, dirigir e encaminhar, no decurso da aprendizagem, a formação do homem". Karling (1991, p. 34) conceitua a didática como sendo "a ciência, a técnica e a arte de bem orientar a aprendizagem e de conseguir que o aluno queira aprender". A didática orienta a ação do professor no alcance do aprendizado e da educação do aluno. Por meio da didática, o professor passa a conhecer os fundamentos e os princípios científicos que fornecem o embasamento do processo ensino-aprendizagem. Pode, também, desenvolver a solução dos problemas sociais por meio do ensino e do saber e tomar decisões adequadas em termos de escolha dos fins, objetivos e meios para o ensino.

A didática se divide em geral e específica. A geral estuda os princípios, as normas e as técnicas que devem regular qualquer tipo de ensino, para qualquer tipo de aluno, ou seja, oferece uma visão geral da atividade docente. Por sua vez, a didática específica é responsável por estudar aspectos científicos de uma determinada disciplina ou faixa de escolaridade. Por meio dela são analisados os problemas e as dificuldades que o ensino de cada disciplina apresenta e organiza, os meios e as sugestões para resolvê-los (PILETTI, 1990). Enquanto área da Pedagogia, segundo Pimenta e Anastasiou (2002), a didática investiga os fundamentos, as condições e os modos de realizar a educação mediante o ensino. Sendo esta uma ação situada em termos históricos, a didática vai se constituindo como teoria do ensino, não para criar regras e métodos válidos para qualquer tempo e lugar, mas para ampliar a preocupação com as demandas que a atividade de ensinar produz, com base em saberes acumulados sobre essa questão.

A didática se constitui como um instrumento fundamental na dinamização do processo de ensino e aprendizagem. Reconhecendo-se que ao ensino se configura como fenômeno complexo e como uma prática social, a função da 
didática é a de compreender o funcionamento do ensino em situação, suas funções sociais e suas implicações estruturais. Além disso, a didática proporciona instrumentos para se realizar uma ação autorreflexiva como componente do fenômeno que estuda, pois é parte integrante do processo de ensino e não uma perspectiva externa que analisa e propõe práticas de ensinar (PIMENTA; ANASTASIOU, 2002).

Cumpre, ainda, ponderar que a didática precisa se colocar em diálogo com outras áreas epistêmicas construídas e em construção, numa perspectiva múlti $e$ interdisciplinar, uma vez que o ensino não se resolve com um único olhar, argumentam Pimenta e Anastasiou (2002). Impende proceder a constantes balanços críticos do conhecimento produzido no seu campo (as técnicas, os métodos, as teorias), para dele se apropriar e criar novos diante das necessidades inovadoras que as situações de ensinar produzem. Como parte do ensino, a didática auxilia a criar respostas novas, assumindo um caráter explicativo e projetivo. No que tange as facilidades disponibilizadas ao professor por meio da didática, Pimenta e Anastasiou (2002, p. 67) acrescentam:

A didática possibilita que os professores das áreas específicas "pedagogizem" as ciências, as artes, a filosofia. Isso é, convertem-nas em matéria de ensino, instituindo os parâmetros pedagógicos (da teoria da educação) e didáti$\cos$ (da teoria do ensino) na docência das disciplinas $e$ articulando-os aos elementos lógico-científicos dos conhecimentos próprios de cada área.

As principais atividades relacionadas à didática, segundo Piletti (1990), compreendem o planejamento, a orientação e o controle do processo de ensino e aprendizagem. No planejamento, efetua-se a previsão e a programação dos trabalhos escolares para um curso ou para cada unidade do plano de curso, ou ainda, para cada aula.

Na etapa do planejamento devem ser considerados os seguintes aspectos elencados por Piletti (1990, p. 44):

a) Características socioeconômicas do bairro ou da região;

b) Características dos alunos;

c) Recursos da região e da escola;

d) Objetivos visados; 
e) Conteúdo necessário para desenvolver o ensino;

f) Número de aulas disponíveis para cada assunto;

g) Métodos e procedimentos que deverão ser desenvolvidos para melhor compreensão, assimilação, organização e fixação do conteúdo;

h) Meios para avaliação e verificação da aprendizagem; $e$

i) Bibliografia básica.

Na fase da orientação, dá-se a execução, por parte do professor, daquilo que foi planejado. Nessa etapa, todas as atividades têm em vista a orientação do aluno para que ele alcance os objetivos propostos. É a fase que requer mais habilidade do professor, visto que é aqui que ele deve exercer, mais do que em outras fases sua função de liderança, objetivando a motivação dos alunos para a aprendizagem. Para tanto, o docente deve recorrer a métodos, técnicas e procedimentos de ensino no intento de criar uma situação favorável à aprendizagem.

A fase de controle no processo de ensino e aprendizagem, por sua vez, incide na constante supervisão do processo de aprendizagem para que seja conduzido de modo eficaz. A eficácia aqui está relacionada ao sucesso na estratégia de aprendizado por parte dos alunos. Portanto, eficácia diz respeito àquela ação que alcança seus resultados, diferindo da eficiência, que compreende apenas a ação realizada em conformidade com as normas estabelecidas, independentemente dos resultados (PILETTI, 1990).

No que tange especificamente à didática na educação superior, tem-se que muitas vezes os professores não são preparados para o exercício da carreira pedagógica. Conforme pontuam Pimenta e Anastasiou (2002), na maior parte das instituições de ensino superior, incluindo as universidades, embora seus professores possuam experiência significativa $e$, inclusive, anos de estudos em suas áreas específicas, predomina o despreparo e até um desconhecimento científico do que vem a ser o processo de ensino e aprendizagem, pelo qual são responsáveis quando ingressam na sala de aula. Comumente, os professores ingressam em departamentos que atuam em cursos aprovados, em que já estão estabelecidas as disciplinas que serão ministradas. A partir daí recebem ementas prontas, planejam individual e solitariamente e é nessas condições que devem ser responsáveis pela docência exercida. Não há uma preocupação por parte do departamento ou do curso de estudar e analisar os resultados obtidos. 
Ademais, os professores da educação superior não recebem orientação em termos de planejamento, metodologia a ser utilizada ou processos avaliatórios a serem empregados, diferentemente do que ocorre com os projetos de pesquisa, que se constituem como uma preocupação institucional. Nesse sentido, Pimenta e Anastasiou (2002) sustentam que a questão da docência na universidade ultrapassa os processos de sala de aula, colocando em discussão as finalidades do ensino de graduação, o que tem sido reconhecido em diferentes países.

Ao examinar o panorama internacional, pode-se constatar nos meios educativos dos países mais avançados um crescimento da preocupação com a formação e o desenvolvimento profissional de professores universitários e com as inovações no campo da didática. Também se observa uma preocupação com a qualidade dos resultados da educação superior, sobretudo daqueles do ensino de graduação, apontando para a relevância da preparação no campo específico e no campo pedagógico de seus docentes. Além disso, novas demandas são colocadas sob responsabilidade desses profissionais, muitas vezes sobrecarregando-os, o que também tem impulsionado estudos e pesquisas na área (PIMENTA; ANASTASIOU, 2002). Outro fator que tem contribuído para o aumento da preocupação com a formação didática do docente universitário é a influência das novas configurações do trabalho na sociedade contemporânea da informação e do conhecimento, das tecnologias avançadas e do Estado mínimo, reduzindo a empregabilidade. Em virtude disso, eleva-se o afluxo dos profissionais liberais, ex-empregados, ao exercício da docência no ensino superior, cuja oferta de empregos se encontra em expansão.

\section{Didática e Gestão do Conhecimento}

A didática aplicada à Gestão do Conhecimento deve envolver o ensino reflexivo, ou seja, um ensinar em que sejam desenvolvidas situações nas quais aprendizes motivados possam desenvolver seus conhecimentos acerca da Gestão do Conhecimento. A noção de aprendizado deve envolver aqui, conforme pontua Cowan (2002), o desenvolvimento de habilidades cognitivas, ao invés do simples exercício incidental de dominar determinado conteúdo dentro de contextos disciplinares individuais. 
Nessa concepção de aprendizado, cabe ao professor o desenvolvimento real de um papel ativo, e mesmo pró-ativo. O professor deve se constituir como uma espécie de orientador, que faz para o aluno comentários construtivos, para que ele se sinta estimulado a buscar o conhecimento. Na clarificação da lavra de Cowan (2002), nas situações de aprendizado e de ensino facilitadores, a influência do docente para chegar a um propósito encontrase restrita à provisão das estruturas e das tarefas iniciais, e também existem aquelas nas quais o envolvimento do professor continua durante a realização de atividades pelos aprendizes.

A mediação reflexiva constitui faina complexa, que exige conhecimentos, afirmam Pimenta e Anastasiou (2002). Devido a isso, a identidade de professores constitui também um processo epistemológico que reconhece a docência como campo de conhecimentos específicos configurados em quatro grandes conjuntos, quais sejam: os conteúdos das diversas áreas do saber (das ciências humanas e naturais, da cultura e das artes) e do ensino; os conteúdos didático-pedagógicos, diretamente ligados ao campo da atividade profissional; os conteúdos condizentes a saberes pedagógicos mais amplos do campo teórico da prática educacional; os conteúdos relacionados à explicitação do sentido da existência humana individual, com sensibilidade pessoal e social.

Todos esses saberes necessitam ser mobilizados articuladamente nos percursos de formação inicial e contínua. De acordo com o magistério de Pimenta e Anastasiou (2002, p. 80), o professor universitário necessita ter o domínio de seu campo específico de conhecimentos:

[...] ter o domínio do conhecimento para ensinar supõe mais do que uma apropriação enciclopédica. Os especialistas, para o serem, precisam se indagar acerca do significado que esses conhecimentos têm para si próprios, o significado desses conhecimentos na sociedade contemporânea, a diferença entre conhecimentos e informações, conhecimento e poder, qual o papel do conhecimento no mundo do trabalho, qual a relação entre ciência e produção material, entre ciência e produção existencial, entre ciência e sociedade informática.

Destarte, para ensinar, o docente precisa conhecer a relação entre os conhecimentos, como as instituições trabalham o conhecimento e quais os 
resultados obtidos, bem como quais as condições existentes nelas para o trabalho com o conhecimento na sociedade atual. O ensino na educação superior necessita trabalhar com métodos alternativos que instiguem a participação do aluno no processo de aprendizagem, diferindo do método tradicional, por meio do qual o aluno fica numa posição passiva e o professor na ativa, no sentido de transmitir conhecimentos e apontar erros cometidos (MARION; MARION, 2006).

O sistema tradicional tem como finalidade central a transferência do conhecimento, do professor para o aluno, e a mensuração do nível de conhecimento atingido. Dessa forma, tem-se que tais métodos estão centrados no professor e ele é o único responsável por mudar as atividades e o comportamento dos alunos. Nesse sistema tradicional, comumente, o professor prepara sua aula antes de ministrá-la. Todavia, esse tipo de ensino se constitui como um menosprezo às capacidades e à inteligência dos alunos (MARION; MARION, 2006).

Ademais, de acordo com o magistério de Zabalza (2004), a divisão proporcionada pela metodologia tradicional entre processo de ensino e de aprendizagem é negativa quando se trata de educação. Em virtude disso, muitos professores não se preocupam com o modo como os alunos aprendem $e$ atribuem os fracassos deles à falta de capacidade, de interesse ou de conhecimentos. Os alunos veem-se obrigados a passar por um processo de aprendizagem abandonados às suas próprias forças e aos seus estilos de trabalho.

Em contraposição ao método de ensino tradicional, emergem outros métodos inovadores, os quais reivindicam o envolvimento maior por parte do estudante nas atividades de ensino-aprendizagem. São esses métodos que o docente universitário deve empregar no ensino da Gestão do Conhecimento, incentivando os alunos a se desenvolverem de forma autônoma, uma vez que os métodos tradicionais se constituem obstáculos para que os estudantes se tornem "pensadores-críticos".

Quando o professor volta suas ações didáticas para o desenvolvimento crítico do aluno, a aprendizagem se torna mais dinâmica. Nesse contexto, possibilita-se aos alunos o desenvolvimento da capacidade de iniciativa de descobrimento, o que torna o processo de aprendizagem contínuo e motiva o crescimento em sua vida profissional. Tanto o aluno quanto o professor são responsáveis pelo processo de ensino e aprendizagem e cabe ao professor exercer o papel de facilitador da aprendizagem, enquanto que o aluno deve ter a liberdade para escolher, expressar-se a agir (MARION; MARION, 2006). 
O surgimento do termo interdisciplinaridade está relacionado à finalidade de corrigir possíveis equívocos e à esterilidade resultante das ciências que se tornaram excessivamente especialistas, sem qualquer comunicação interdisciplinar. De acordo com Santomé (1998), em virtude dessa especialização, emergiram alguns fatores que dificultam a efetivação do processo de interdisciplinaridade, como as paredes que são construídas no interior das disciplinas isoladas e a divisão entre trabalho de pesquisa e de aplicação, o que é consequência da divisão de trabalho (manual e intelectual) existente nas sociedades de estrutura capitalista.

Nesse sentido, o ensino da Gestão do Conhecimento precisa lidar com essas barreiras impostas à interdisciplinaridade, superando as barreiras que isolaram as disciplinas e conciliando a pesquisa e a aplicação do conhecimento gerado. A necessidade da interdisciplinaridade deve-se ao fato de a Gestão do Conhecimento lidar com diferentes aspectos dentro da organização, os quais se encontram em constante interação, como a tecnologia, os dados, as informações, o capital humano, o capital intelectual, entre outros recursos necessários para o desenvolvimento e o compartilhamento do conhecimento. Além disso, a própria organização se compõe como um sistema de interações, as quais se constituem tanto no ambiente interno quanto no externo.

Desse modo, a interdisciplinaridade no ensino está pautada na internacionalização da vida social, econômica, política e cultural. Por isso, entender o significado das propostas curriculares integradas implica na consideração das dimensões globais da sociedade e do mundo no qual se vive.

A interdependência é uma das palavras mais indispensáveis nos novos modelos de vida e sociedade. O poder $e$, portanto, as questões políticas, econômicas, culturais, religiosas e militares estão cada vez mais inter-relacionadas (sic), e além disso seus cenários são mais internacionais (SANTOMÉ, 1998, p. 84).

O processo didático de desenvolvimento da interdisciplinaridade no ensino da Gestão do Conhecimento, da mesma forma que ocorre nas demais disciplinas, envolve várias fases. Conforme explica Braga (1999), a primeira delas compreende a integração, correlacionando diversas disciplinas que são desenvolvidas separadamente. Apenas em alguns momentos é estabelecida uma coordenação planejada, quando as partes de cada uma delas, para serem mais bem compreendidas, necessitam de conteúdos típicos das outras. 
A segunda etapa da ótica interdisciplinar reside na integração por meio de temas, tópicos, ou ideias, que passam a constituir a base das distintas áreas de conhecimento ou disciplinas. É possível integrar uma ampla gama de conteúdos e atividades de diversas disciplinas. Tais disciplinas são atravessadas por um interesse comum e, ao mesmo tempo, se defrontam com as dificuldades de um trabalho integrado, uma vez que passam a se subordinar à ideia que serve para governar a proposta de integração.

A terceira etapa compreende a integração em torno de uma questão prática e diária. Há problemas cotidianos, cuja compreensão e avaliação requerem conhecimentos, habilidades e procedimentos que não se localizam especificamente em uma disciplina e sim em diversas. Esses são os denominados problemas transversais e a forma de fazer frente aos mesmos pressupõe propostas de trabalho integrado.

Por fim, a quarta forma de integração que é proporcionada pela interdisciplinaridade, segundo propõe Braga (1999), ocorre por meio de temas ou investigações propostas pelos alunos. A diferença dessa modalidade de integração em relação às anteriores é a de que os próprios alunos decidem o tema ou problema que será empregado como eixo para organizar os conteúdos das diferentes áreas de conhecimento.

Por conseguinte, pensando a interdisciplinaridade como transformadora das relações universitárias, é importante que os professores das diferentes especialidades, na universidade, passem a trabalhar conjuntamente. A organização universitária tem como tarefa facilitar o trânsito entre os departamentos para o exercício epistemológico interdisciplinar e o desenvolvimento dos projetos de pesquisa. Além de uma didática direcionada para a interdisciplinaridade, o ensino da Gestão do Conhecimento precisa estar em constante atualização em termos de materiais didáticos, uma vez que a realidade da organização na qual a Gestão do Conhecimento se aplica pressupõe constantes inovações. Assim, da mesma forma que o ensino como um todo é resultado da realidade atual da sociedade, também a Gestão do Conhecimento precisa se adequar às necessidades do mercado.

Schafranski (2003) afirma que as dinâmicas da sociedade contemporânea solicitam que a prática educativa guarde relações com as transformações e exigências do contexto atual, no qual a educação e a aquisição de conhecimentos passam a se constituir em pontos estratégicos para o desenvolvimento econômico e social. Com base nessas condições são impostas novas solicitações à educação, de acordo com os significativos avanços das forças 
produtivas, que vieram gerar uma nova cultura, centrada no conhecimento científico e tecnológico, tidos hodiernamente como o mais efetivo fator de produção no mundo capitalista. Paralelamente,em que é necessário existir uma relação entre a prática educativa e as transformações sociais, também a formação dos professores universitários deve ser continuada, pois, conforme salientam Pimenta e Anastasiou (2002), a qualificação se constitui como um fator-chave no fomento da qualidade em qualquer profissão, sobretudo na educação, que experimenta mudanças constantes.

Zabalza (2004) destaca que o exercício da profissão docente requer uma sólida formação, não apenas nos conteúdos próprios da disciplina, mas também nos aspectos correspondentes a sua didática e ao encaminhamento das diversas variáveis que caracterizam a docência. $\mathrm{O}$ autor também pontua que a formação dos professores universitários, no sentido de qualificação científica e pedagógica compreende um dos fatores centrais da qualidade da universidade. Por conseguinte, um dos desafios que se faz presente na atualidade em termos de formação dos docentes universitários é ter a orientação distinta para sua função, transformando-os em profissionais da "aprendizagem", em vez de especialistas que conhecem bem um tema e sabem explicálo, deixando a tarefa de aprender como função exclusiva do aluno, o qual terá de se esforçar significativamente até conseguir assimilar, de fato, o que o professor tentou lhe ensinar (ZABALZA, 2004).

Na compreensão de Zabalza (2004), antes do compromisso com a disciplina, o docente possui um compromisso em relação aos alunos, razão pela qual ele deve servir como facilitador, fazendo o que estiver ao seu alcance para que os alunos tenham acesso intelectual aos conteúdos e as práticas da disciplina. Portanto, o professor deve possuir a competência científica, relacionada ao conhecimento do âmbito científico ensinado, e a competência pedagógica, ligada ao comprometimento do docente com a formação e com a aprendizagem dos estudantes. O professor necessita ampliar os conhecimentos que tem acerca da aprendizagem e sobre a forma como os alunos aprendem. Quanto mais o professor aprofundar seus conhecimentos em relação à aprendizagem, melhores serão as condições para facilitá-la. Assim sendo, na ausência de conhecimentos suficientes sobre o assunto, o professor tende a conceber a aprendizagem alheia em função dos parâmetros pelos quais ele mesmo aprende (ZABALZA, 2004).

Outro importante aspecto a ser enfocado na didática do ensino da Gestão do Conhecimento diz respeito à ênfase no dueto prática e teoria. No en- 
tender de Marion e Marion (2006), inexistem dúvidas acerca do fato de que o fundamento para os discípulos em geral esteja situado essencialmente em conceitos. No entanto, a prática desses conceitos é indispensável para melhor sedimentação da aprendizagem. Marion e Marion (2006) não pretendem afirmar que a melhor metodologia consiste em primeiro ensinar a teoria e, em seguida, a prática. Em determinadas situações, torna-se mais adequado ensinar a prática em primeiro lugar, visto que, por exemplo, uma criança aprende primeiro a falar para depois aprender a norma oficial da língua.

As atividades práticas em laboratório, os estudos de caso, jogos, entre outras atividades de simulação permitem aos estudantes a oportunidade de entrarem em contato com experiências que reforçam os conceitos apresentados em sala de aula. Dentro dessa perspectiva, tal prática deverá ser empregada para praticamente todos os pontos. No entanto, o professor pode optar por despertar em primeiro lugar a prática para, posteriormente, expor a teoria em sala de aula que explica aquela prática. O ensino de uma teoria que justifica a prática adiciona valor e utilidade ao processo de ensino e aprendizagem (MARION; MARION, 2006). Ainda conforme Marion e Marion (2006), o aumento do tempo disponível para a discussão de casos é atividade que pode ser concretizada quando algumas atividades típicas de sala de aula podem ser transformadas em atividades práticas.

Destarte, testes, exames e outras avaliações podem ser realizados em campo, com base em situações reais, proporcionando mais tempo disponível para a interação professor/estudante e estudante/estudante na sala de aula. Simulações computadorizadas e aplicativos no computador, além de experimentos comportamentais que são componentes importantes das atividades de laboratório. A associação constante entre teoria e prática é substancial quando se trata do ensino da Gestão do Conhecimento. É fundamental que os alunos tenham contato com diferentes situações que perpassam as organizações para aprenderem a dirimir problemas recorrendo à teoria que lhes é apresentada pelo docente.

\section{Considerações Finais}

Em virtude da importância do conhecimento, as organizações necessitam geri-lo de forma correta e a metodologia da Gestão do Conhecimento auxilia o emprego eficaz dos dados e informações, transformando-os em co- 
nhecimento. desse modo, por meio da gestão, o conhecimento, que é propriedade individual, tende a ser identificado e compartilhado na organização, agregando valor às tarefas dos que o detém e contribuindo para o alcance de resultados otimizados por parte da organização.

Ao abordar a didática aplicada à Gestão do Conhecimento, emerge que tal disciplina é fundamental para a qualidade do ensino, uma vez que contribui para o direcionamento eficaz do processo de ensino e aprendizagem. A didática auxilia no planejamento, na orientação e no acompanhamento da aprendizagem do aluno, disponibilizando ao docente diferentes métodos e técnicas que o ajudam a criar situações de aprendizado.

É importante salientar que no ensino da Gestão do Conhecimento a relação entre aluno e professor não deve se realizar de forma unidirecional: o professor explicando o conteúdo e o aluno simplesmente absorvendo. Esse método tradicional não contribui para o verdadeiro aprendizado, porquanto o aluno permanece sempre numa posição estática e não participa ativamente do ensino. O professor deve desenvolver atividades de tal forma que instigue o aluno a participar, dando-lhe liberdade de escolha. Nesse sentido, a função central do professor é atuar como facilitador do processo de aprendizagem do aluno.

No ensino da Gestão do Conhecimento, o docente deve focar o desenvolvimento da capacidade reflexiva dos seus alunos e a dinamicidade do ensino. Dessa forma, torna-se relevante o ensino interdisciplinar, pois permite que o aluno possa manejar referenciais teóricos, conceitos, procedimentos, habilidades de disciplinas diversas, no intento de compreender ou solucionar as questões e problemas propostos. Logo, é fundamental que o professor faça uso de atividades por meio das quais os alunos possam verificar o funcionamento dos ensinamentos teóricos na prática. Em outros termos, isso significa que deve haver uma constante interação entre doutrina e práxis para que o aluno desenvolva conhecimentos concretos sobre o funcionamento da Gestão do Conhecimento no âmbito das organizações.

Nos cursos de graduação em administração, configura-se o desafio de fomentar um conhecimento generalizador, simultaneamente filosófico, pragmático, sociológico, econômico, psicológico qualitativo e quantitativo, institucionalizado pelas Diretrizes Curriculares Nacionais do Curso de Graduação em Administração.

A par dos conteúdos de formação básica, os quais devem prover os diversos campos do conhecimento exigidos pela referida Resolução, tais como 
Filosofia, Psicologia, Sociologia, Ciência Política, Informática, Direito, Economia, Metodologia Científica, dentre outras, verifica-se a necessidade de acrescer a Gestão do Conhecimento e sua didática. Essa disciplina é de essencial importância e fundamenta a compreensão e eficácia das disciplinas subsequentes de conteúdo profissionalizante. Enfim, fica patente que se faz mister contemplar a Gestão do Conhecimento não apenas nos cursos de pósgraduação, mas também no âmbito do bacharelado.

\section{Didactics of the Management of Knowledge in Courses of Graduation in Administration}

\section{Abstract}

In information society, gets transformed into the key-factor of post-industrial economy and the main occupational change determinant. Knowledge Management becomes an important methodology at disposal of the organizations, which contributes to create, share and spread the knowledge in order to help the organization face, as well as possible, the forces of the environment exerts over the organization. The Knowledge Management must focus multidisciplinary and reflexive teaching. In the teaching of Knowledge Management, the pedagogical relations shouldn't get configured in a unidirectional form, but allow the participation of the student, making the teacher a facilitator of the learning process. This paper, guided by the deductive method, aims at analyzing the role of didactics in the Knowledge Management in the area of undergraduate courses in Management, reaping the completion of its relevance to the development of professional skills normalized to the professional egress of the mentioned course.

Key-words: Knowledge Management. Education. Information Society.

\section{Referências}

ANTUNES, Maria Thereza Pompa. Capital intelectual. São Paulo: Atlas, 2000.

BRAGA, Ana Maria. Reflexões sobre a superação do conhecimento fragmentado nos cursos de graduação. In: LEITE, Denise (Org.). Pedagogia universitária: conhecimento, ética e política no ensino superior. Porto Alegre: UFRGS, 1999. 
BRASIL. Conselho Nacional de educação. Resolução $\mathbf{n}^{\circ}$ 4, de 13 de julho de 2005. Disponível em: <http://portal.mec.gov.br/cne/arquivos/pdf/ rces004_05.pdf >. Acesso em: 20 maio 2009.

CALDAS, Ricardo W.; AMARAL, Carlos Alberto A. Mudanças, razão das incertezas: introdução à gestão do conhecimento. São Paulo: Cla, 2001.

CHOO, Chun Wei. A organização do conhecimento: como as organizações usam a informação para criar significado, construir conhecimento e tomar decisões. São Paulo: Senac, 2003.

COWAN, John. Como ser um professor universitário inovador: reflexão na ação. Porto Alegre: Artmed, 2002.

DRUCKER, Peter Ferdinand. Desafios gerenciais para o século XXI. São Paulo: Pioneira, 1997.

$\overline{2001 .}$

. O melhor de Peter Drucker: obra completa. São Paulo: Nobel,

FLEURY, Afonso; FLEURY Maria Tereza Leme. Estratégias empresariais e formação de competências: um quebra-cabeça caleidoscópico da indústria brasileira. 3. ed. São Paulo: Atlas, 2004.

KARLING, Argemiro Aluísio. A didática necessária. São Paulo: IBRASA, 1991.

KUMAR, Krishan. Da sociedade pós-industrial à pós-moderna: novas teorias sobre o mundo contemporâneo. Rio de Janeiro: Jorge Zahar, 1997.

LAPA, Eduardo. Gestão do conteúdo: como apoio à Gestão do Conhecimento. Rio de Janeiro: Brasport, 2004.

LARA, Consuelo Rocha Dutra de. A atual gestão do conhecimento: a importância de avaliar e identificar o capital humano nas organizações. São Paulo: Nobel, 2004.

MARION, José Carlos; MARION, Arnaldo Luís Costa. Metodologias de ensino na área de negócios. São Paulo: Atlas, 2006.

PILETTI, Claudino. Didática geral. 11. ed. São Paulo: Ática, 1990. 
PIMENTA, Selma Garrido; ANASTASIOU, Lea das Graças Camargos.

Docência no ensino superior, v. 1. São Paulo: Cortez, 2002.

RESENDE, Enio. O livro das competências: desenvolvimento das competências: a melhor auto-ajuda para pessoas, organizações e sociedade. 2. ed. Rio de Janeiro: Qualitymark, 2003.

RUAS, Roberto; ANTONELLO, Claudia Simone; BOFF, Luiz Henrique. Os novos horizontes da gestão: aprendizagem organizacional e competências. Porto Alegre: Bookman, 2005.

SANTOMÉ, Jurjo Torres. Globalização e interdisciplinaridade: o currículo integrado. Porto Alegre: Artes Médicas, 1998.

SCHAFRANSKI, Márcia Dérbli. Pedagogia no ensino superior: sociedade cognitiva. Curitiba: Juruá, 2003.

SILVA FILHO, Cândido Ferreira da; SILVA, Lucas Frazão (Orgs.). Tecnologia da informação e gestão do conhecimento. Campinas: Alínea, 2005.

ZABALZA, Miguel A. O ensino universitário: seus cenários e seus protagonistas. Porto Alegre: Artmed, 2004.

ZABOT, João Batista M.; SILVA, L. C. Mello da. Gestão do conhecimento: aprendizagem e tecnologia construindo a inteligência coletiva. São Paulo: Atlas, 2002. 